\title{
LOS MONTES DE LA COSTA DEL SOL. SIERRA BERMEJA Y SIERRA CRESTELLINA
}

\author{
José Gómez Zotano \\ Instituto de Desarrollo Regional \\ Universidad de Granada
}

\section{RESUMEN}

En este artículo se analiza la significación que tienen en la actualidad los montes existentes en Sierra Bermeja y Sierra Crestellina, trasfondo montañoso de la Costa del Sol Occidental. En primer lugar se analiza el régimen jurídico de los montes, tanto públicos como privados. En segundo lugar se hace una breve descripción histórica del papel que tenía el monte dentro del modelo de explotación tradicional, vigente hasta fechas relativamente recientes. En tercer lugar se analiza la ordenación reciente de los montes y sus aprovechamientos. Finalmente, en la cuarta parte, planteamos evidentes conflictos de intereses tras la quiebra del sistema tradicional de manejo y explotación del monte frente a las nuevas funciones, haciendo hincapié en los procesos de urbanización ligados al turismo y en la protección de los espacios naturales y la política medioambiental.

Palabras clave: Montes, Sierra Bermeja, Sierra Crestellina, Provincia de Málaga, conflictos de uso.

\section{ABSTRACT}

This article analyzed the present time mounts in Bermeja Mountain range and Crestellina Mountain range, mountains of the Costa del Sol. In the first place the legal regime of mounts, as much public is analyzed as prevailed. Secondly a brief historical description is made of the paper that had the mount within the model of traditional operation, effective until relatively recent dates. Thirdly one analyzes the recent arrangement of mounts and its advantages. Finally, in the fourth part, we as opposed to raised evident conflicts of interests after the bankruptcy of the traditional system of handling and operation of the mount the new functions, insisting on the processes of urbanization bound to the tourism and in the protection of the natural spaces and the environmental policy.

Key words: Mounts, Sierra Bermeja, Sierra Crestellina, Province of Málaga, use conflicts. 


\section{Introducción}

La organización de los espacios naturales, y en concreto de la montaña, se encuentra hoy día en una encrucijada entre las antiguas y las nuevas funciones. Ya en su misma situación encontramos uno de los rasgos más característicos y originales del ámbito de estudio, nos referimos al hecho de que Sierra Bermeja y Sierra Crestellina ejercen como nexo de unión entre ámbitos geográficos como la Costa del Sol Occidental y la Serranía de Ronda. Estas comarcas malagueñas si bien se complementan entre sí, resultan ser muy distintas y diferenciadas, por lo que Sierra Bermeja y Sierra Crestellina se ven sometidas a una doble funcionalidad que genera importantes conflictos de uso. En este sentido, la organización de estas sierras, así como del resto de los espacios naturales que conforman el trasfondo montañoso de la Costa del Sol, está compuesta por dos niveles o grupos diferentes de afecciones jurídico-administrativas que se debaten entre las antiguas y las nuevas funciones de las áreas de montaña. Por un lado nos encontramos con el régimen jurídico tradicional de los montes, mientras que por el otro está el paquete de medidas encaminas a proteger los espacios naturales más valorados.

Esta reordenación de la montaña ha supuesto una pérdida de protagonismo de los montes frente a otras figuras jurídicas menos consolidadas, especialmente en montañas como Sierra Bermeja, expuesta a una fuerte presión urbanística derivada de municipios eminentemente turísticos como Marbella, Estepona, Benahavís, Casares o Istán, que basan su crecimiento económico en los ingresos procedentes de las licencias urbanísticas.

Desde un punto de vista físico, cabe destacar que Sierra Bermeja constituye uno de los afloramientos ultramáficos más grandes del mundo, rocas conocidas internacionalmente como peridotitas de Ronda. Como veremos, tanto por la toxicidad de este tipo de rocas como por la homogeneidad y masividad que presenta el afloramiento peridotítico, el uso y establecimiento de los montes se han visto fuertemente condicionados por esta singularidad geológica.

Por todo ello, creemos conveniente analizar la significación que tienen en la actualidad los montes de estas montañas, incidiendo en aspectos relativos a su manejo y explotación, y teniendo en cuenta que a lo largo de la historia la titularidad de estos predios ha influido sobremanera en el paisaje de buena parte de la Costa del Sol.

Para realizar dicho análisis tomaremos en consideración, de forma preferente, los denominados montes públicos, aunque trataremos de incidir también, en la medida en que nos lo permita la información disponible, sobre la realidad que presentan los montes particulares o de dominio privado.

\section{Régimen jurídico de los montes}

La Ley de Montes vigente en la actualidad fue aprobada el 8 de junio de 1957. Se trata de una legislación básica que pretende regular la conservación y aprovechamiento de los montes y las masas forestales, su regeneración y la planificación que sobre ellas se realiza.

Atendiendo a las definiciones de Neira y Martínez (1973) calificamos como monte aquel «terreno dedicado a la producción de madera u otros productos forestales, o que se mantienen con vegetación leñosa para alguna finalidad, tal como protección del suelo, contención de las aguas o recreo». El apelativo de público se aplica a todos aquellos montes que son «propiedad de una administración pública, abstracción hecha de su naturaleza y régimen» (Guaita, 1976). Estos montes, incluidos en el Catálogo de Utilidad Pública son inajenables; salvo caso de prevalencia sobre otra utilidad pública como pueden ser infraestructuras del Estado o de la Defensa, son inembargables y son imprescriptibles; es decir, que no prescribe su condición con la ocupación o el uso que en ellos se haga. 
Con respecto a su administración, los Montes de Utilidad Pública están protegidos por el artículo $29^{\circ}$ de su Ley, y el $202^{\circ}$ de su Reglamento mediante el establecimiento de criterios que pueden ser de enorme utilidad para la comprensión del estado actual de estas montañas:

$1^{o}$. Los aprovechamientos de los productos forestales tendrán que hacerse dentro de unos límites que permitan los intereses de su conservación y mejora.

$2^{o}$. Los montes del Catálogo se someterán a proyectos de ordenación económica ${ }^{l}$ y, en tanto estos no sean aprobados, se aprovecharán con arreglo a los planes técnicos adecuados.

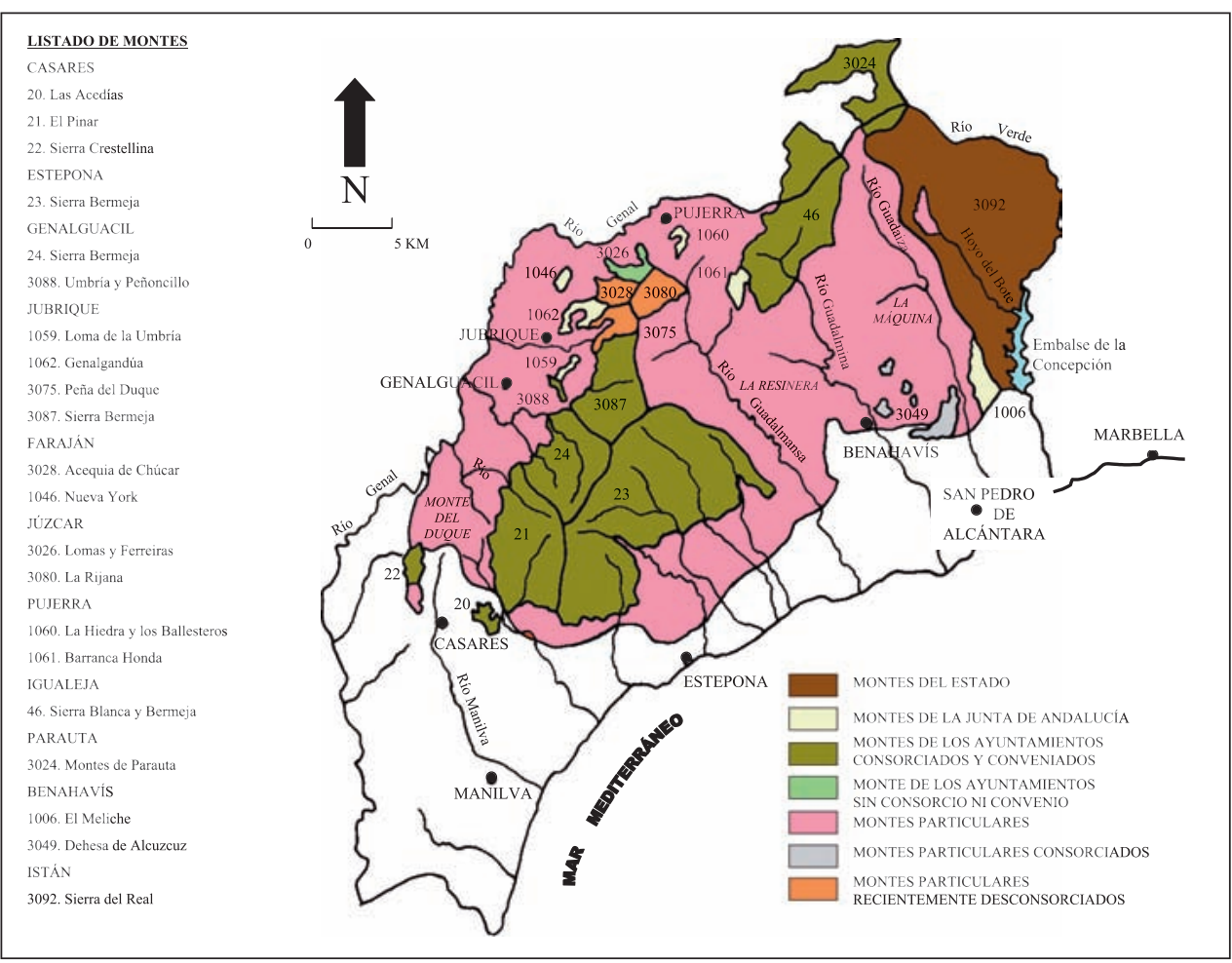

Figura 1. Mapa de los montes públicos y privados de Sierra Bermeja y Sierra Crestellina.

Fuente: Elaboración propia a partir de los datos de la Consejería de Medio Ambiente² y Garzón Blanco (1999).

1 Los Proyectos de Ordenación de Montes que planifican sus aprovechamientos suponen uno de los primeros instrumentos de planificación territorial conocidos en nuestro país, pues datan de más de un siglo de antigüedad. Esta herramienta tiene como finalidad esencial la ordenación del espacio, la persistencia del monte y su normal restauración en el menor tiempo posible. Asimismo han de regirse por el principio del suministro sostenido de productos a la comunidad titular. En los montes regidos por este tipo de planificación, el aspecto económico de los aprovechamientos quedará subordinado al tratamiento silvícola que, en cada caso, sea más adecuado para la finalidad protectora perseguida. Estos planes normalmente contienen una primera parte de inventario donde se analiza el estado legal, el estado natural, el estado forestal, el estado económico, una segunda parte de ordenación y una tercera parte de plan especial.

2 Estos datos han sido facilitados por la delegación en Málaga de la Consejería de Medio Ambiente, donde disponen tanto de la cartografía a escala 1:50.000 de los Montes de Utilidad Pública, como de los Planes de Aprovechamientos fijados por distintos organismos a lo largo de la historia. 
$3^{\circ}$. En el plan de mejoras de carácter obligatorio se podrá incluir cualquiera que se estudie y justifique en el más amplio sentido del concepto de mejoras de orden técnico, social, económico o financiero que contribuyan a la prosperidad de la finca.

Por su parte, respecto a los montes particulares, la vigente Ley de Montes afirma que los mismos «podrán ser sometidos a la intervención de la Administración en lo referente a sus aprovechamientos que los regulará con vistas a la persistencia de los predios».

Estas definiciones han sido aplicadas también por autores como Araque Jiménez (1990), del cual tomaremos el análisis de las distintas formulas de relación contractual que la Administración del Estado contrae con los Ayuntamientos y propietarios privados de montes. Éstas fórmulas de relación pretenden emprender aquellas mejoras territoriales que difícilmente podrían llevarse a cabo sin el concurso de la iniciativa estatal, haciendo muy compleja la situación jurídica actual de estos montes en torno a la propiedad y explotación de los mismos. Los grandes grupos de propietarios podrían resumirse en montes del Estado, de la Junta de Andalucía, de los Ayuntamientos y de los particulares.

Esta realidad espacial podemos apreciarla en el mapa de los montes (Fig. 1), donde se refleja tanto la significación superficial de los distintos grupos de montes, como la posición exacta que ocupa cada uno de ellos en el macizo peridotítico de Sierra Bermeja y el espolón marmóreo de Sierra Crestellina.

\subsection{Montes del Estado}

Los montes del Estado han sufrido una gran merma desde principios del siglo XX, siendo la última de ellas el monte denominado «El Meliche». Por ésta razón, como podemos apreciar en el mapa anterior, la propiedad del Estado se restringe en Sierra Bermeja únicamente al municipio de Istán. Se trata del monte denominado «Sierra del Real», que constituye un vasto predio de cerca de 6.000 has, tal y como podemos comprobar en la tabla que nos ofrece los datos básicos del mismo (Tabla 1).

El monte «Sierra del Real», instalado en la parte más oriental de Sierra Bermeja, se encuentra dividido en dos partes atendiendo al sustrato geológico; «Sierra del Real A» sobre peridotitas y «Sierra del Real B» sobre esquistos y gnéises. El monte «Sierra del Real A», propiedad del Instituto Nacional de Previsión, fue adquirido anteriormente por la Unión Resinera Bilbaína. Esta empresa estuvo interesada en esta parte del Monte al estar poblada de pinos negrales susceptibles de resinación. Por su parte, el Monte «Sierra del Real B» fue adquirido en 1962 también por el Instituto Nacional de Previsión. En este monte, poblado principalmente de alcornoques y quejigos, los aprovechamientos quedan limitados a los vecinos de Istán, que pueden igualmente, pero con limitaciones, recoger palmitos, esparto y leñas muertas. En lo referente al corcho, el 15\% del beneficio líquido de cada operación

Tabla 1

MONTES DEL ESTADO

\begin{tabular}{|c|c|c|c|c|c|}
\hline $\begin{array}{c}\text { TÉRMINO } \\
\text { MUNICIPAL }\end{array}$ & $\begin{array}{c}\text { NOMBRE DEL } \\
\text { MONTE }\end{array}$ & $\begin{array}{c}\text { SUPERFICIE } \\
\text { HAS. }\end{array}$ & LITOLOGÍA & $\begin{array}{c}\text { ORGANISMO } \\
\text { ADMINISTRADOR }\end{array}$ & $\begin{array}{c}\text { ESTADO DE LA } \\
\text { ORDENACIÓN }\end{array}$ \\
\hline Istán & Sierra del Real & $5.721,69$ & $\begin{array}{l}\text { Peridotitas y } \\
\text { esquistos }\end{array}$ & C.M.A. (JJ.AA) & Revisión 2004 \\
\hline
\end{tabular}

Fuente: Consejería de Medio Ambiente. Elaboración propia. 
le corresponde al Sindicato Agrícola de Istán. El número de cabezas de ganado que puede pastar queda fijado anualmente por el Distrito Forestal de Málaga, siendo el beneficio para el Ayuntamiento (Juan y Díaz, 1965).

En cuanto al Estado de la Ordenación se ha finalizado la revisión en el año 2004 (la última revisión realizada se remontaba a 1965). En la actualidad presenta el enclavado del Hoyo del Bote y está consorciado con la Junta de Andalucía. Aún mantiene una carga a favor de los vecinos del pueblo de Istán.

\subsection{Montes de la Junta de Andalucía}

La Junta ha emprendido acciones para hacerse con el control de ciertos montes propiedad del Estado, como «El Meliche», en Benahavís. Hasta el momento dicha acción ha afectado a pequeñas superficies forestales (no superiores a 400 has), aunque es de esperar que en el futuro tal política de compras afecte a otros montes. Los montes de la Junta de Andalucía son, aparte del ya mencionado, «Nueva York» en Faraján, «Genalgandúa» y «Loma de la Umbría» en Jubrique y «Barranca Honda» y «La Hiedra y los Ballesteros» en Pujerra. En el mapa de montes aparecen representadas estas propiedades distribuidas fundamentalmente por el Valle del Genal. Las características generales de estos predios pueden observarse en la tabla 2 .

Tabla 2

RELACIÓN DE MONTES PROPIEDAD DE LA JUNTA DE ANDALUCÍA

\begin{tabular}{|l|c|c|c|c|c|}
\hline $\begin{array}{c}\text { TERMINO } \\
\text { MUNICIPAL }\end{array}$ & $\begin{array}{c}\text { NOMBRE DEL } \\
\text { MONTE }\end{array}$ & $\begin{array}{c}\text { SUPERFICIE } \\
\text { HAS. }\end{array}$ & LITOLOGÍA & $\begin{array}{c}\text { ORGANISMO } \\
\text { ADMINISTRADOR }\end{array}$ & $\begin{array}{c}\text { ESTADO DE LA } \\
\text { ORDENACIÓN }\end{array}$ \\
\hline Benahavís & El Meliche & 368,10 & $\begin{array}{c}\text { Peridotitas y } \\
\text { esquistos }\end{array}$ & C.M.A. (JJ.AA) & Ordenación 2002 \\
\hline Faraján & Nueva York & 74 & Esquistos & C.M.A. (JJ.AA) & Sin ordenar \\
\hline \multirow{2}{*}{ Jubrique } & Genalgandúa & 179,50 & Esquistos & C.M.A. (JJ.AA) & Ordenación 2002 \\
\cline { 2 - 7 } & $\begin{array}{c}\text { Loma de la } \\
\text { Umbría }\end{array}$ & 57,35 & Esquistos & C.M.A. (JJ.AA) & Ordenación 2002 \\
\hline \multirow{2}{*}{ Pujerra } & $\begin{array}{c}\text { Barranca } \\
\text { Honda }\end{array}$ & 80 & $\begin{array}{c}\text { Peridotitas y } \\
\text { esquistos }\end{array}$ & C.M.A. (JJ.AA) & Ordenación 2002 \\
\cline { 2 - 7 } & $\begin{array}{c}\text { La Hiedra y } \\
\text { los Ballesteros }\end{array}$ & 130,3 & Esquistos & C.M.A. (JJ.AA) & Ordenación 2002 \\
\hline
\end{tabular}

Fuente: Consejería de Medio Ambiente. Elaboración propia.

\subsection{Montes de los Ayuntamientos}

Los montes de los Ayuntamientos son los espacios públicos que predominan superficialmente en Sierra Bermeja (con casi 15.000 has) y Sierra Crestellina (300 has.). Como podemos observar en el mapa de montes, Sierra Bermeja, a pesar de constituir una clara unidad estructural, presenta sin embargo una configuración muy fragmentada de las propiedades que responde a la división en los términos municipales. Esta configuración va siguiendo casi siempre las divisorias de aguas, hecho constatado por algunos autores (Gómez Moreno, 1987). 
A excepción de Benahavís, Istán, Faraján, Pujerra y Marbella, el resto de los municipios de la comarca mantienen hoy bajo su dominio algún monte en Sierra Bermeja y/o Sierra Crestellina. Son Casares, Estepona, Genalguacil, Jubrique, Júzcar, Igualeja y Parauta los municipios que han sabido o podido conservar los montes secularmente. El predio más extenso es el de Estepona (4.900 has), seguido del de Igualeja. En estos montes se conservan dos de los tres pinsapares de Sierra Bermeja, el de Los Reales y el del Cerro Abanto. No obstante los montes de propios han perdido la supremacía que han mantenido secularmente sobre los estatales.

Si relacionamos la superficie con la litología (Tabla 3), nos damos cuenta de que los montes que se establecen sobre tierras roturables (esquistos) representan una mínima parte del total, ya que el porcentaje mayor parte se asienta principalmente sobre peridotitas, sustrato que no permite el uso agrícola (Fig. 2).

Tabla 3

RELACIÓN DE MONTES DE PROPIOS DE SIERRA BERMEJA

\begin{tabular}{|c|c|c|c|c|c|}
\hline $\begin{array}{c}\text { MUNICIPIO } \\
\text { PROPIETARIO }\end{array}$ & $\begin{array}{l}\text { NOMBRE DEL } \\
\text { MONTE }\end{array}$ & $\begin{array}{l}\text { SUPERFICIE } \\
\text { HAS. }\end{array}$ & LITOLOGÍA & $\begin{array}{c}\text { ORGANISMO } \\
\text { ADMINISTRADOR }\end{array}$ & $\begin{array}{l}\text { ESTADO DE LA } \\
\text { ORDENACIÓN }\end{array}$ \\
\hline \multirow{3}{*}{ Casares } & El Pinar & $1.714,20$ & Peridotitas & C.M.A. (JJ.AA) & Ultima revisión 1971 \\
\hline & Las Acedías & 71,35 & Esquistos & C.M.A. (JJ.AA) & Ordenación 2004 \\
\hline & Sierra Crestellina & 300 & Mármoles & C.M.A. (JJ.AA) & Sin ordenar \\
\hline Estepona & Sierra Bermeja & $4.899,81$ & Peridotitas & C.M.A. (JJ.AA) & Revisión 2004 \\
\hline \multirow[t]{2}{*}{ Genalguacil } & $\begin{array}{l}\text { La Umbría y } \\
\text { Peñoncillo }\end{array}$ & 31,6 & Esquistos & C.M.A. (JJ.AA) & Sin ordenar \\
\hline & Sierra Bermeja & 1.273 & Peridotitas & C.M.A. (JJ.AA) & Ultima revisión 2000 \\
\hline Igualeja & $\begin{array}{c}\text { Sierra Blanca y } \\
\text { Bermeja }\end{array}$ & $\begin{array}{c}3.126 \\
\text { (2.018 en Sierra } \\
\text { Bermeja) }\end{array}$ & Peridotitas & C.M.A. (JJ.AA) & Ultima revisión 2002 \\
\hline Jubrique & Sierra Bermeja & 1.101 & Peridotitas & C.M.A. (JJ.AA) & Revisión en 2001 \\
\hline Júzcar & Lomas y Ferreiras & 280 & Esquistos & Ayuntamiento & Plan Técnico \\
\hline Parauta & Montes de Parauta & $\begin{array}{c}\text { 1.092,97 (Parte en } \\
\text { Cerro Abanto) }\end{array}$ & Peridotitas & C.M.A. (JJ.AA) & Ordenación 2001 \\
\hline
\end{tabular}

* Al traspasar estos montes los límites de Sierra Bermeja, únicamente especificamos la litología que presenta en esta montaña, ya que el resto de la superficie de dichos montes se establece sobre calizas jurásicas de la Sierra de las Nieves.

Fuente: Consejería de Medio Ambiente. Elaboración propia.

La presión demográfica ha relegado históricamente a los medios no roturables — peridotitas y mármoles - estos predios. En la actualidad sólo quedan algunos vestigios respecto a la extensión superficial que ocupaban en el pasado. Recordemos que durante la Desamortización los montes que corrieron mejor suerte mermaron su extensión, mientras que los montes de propios de Marbella cayeron en manos de las siderurgias de Río Verde. Tras la Desamortización, en Benahavís la propiedad privada respondió al interés por constituir explotaciones forestales con la implantación de La Unión Resinera Española, importante empresa del sector maderero (Gómez Moreno, 1989; Gómez Zotano, 2004). 


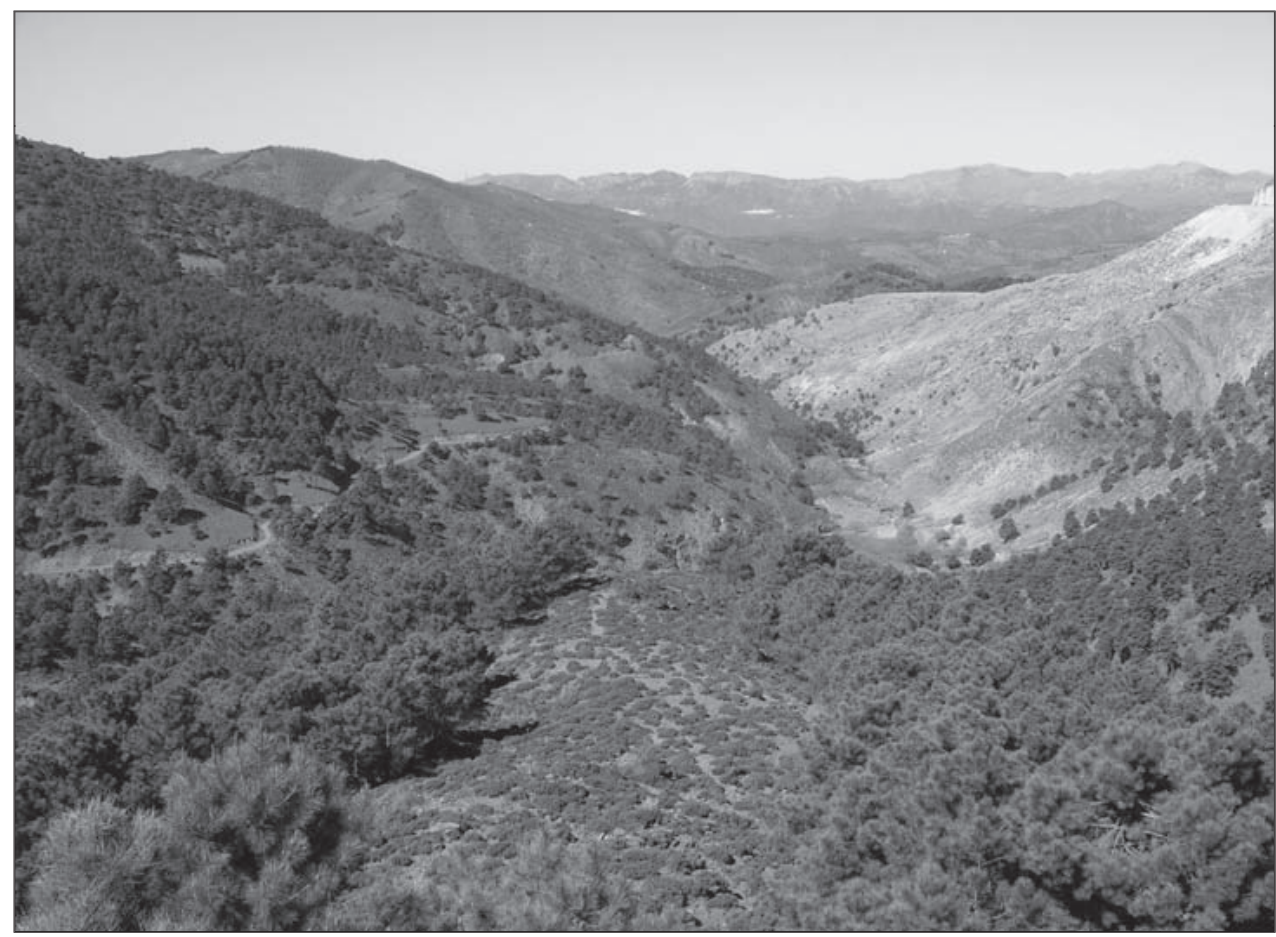

FiguRa 2. Contacto geológico entre los mármoles y las peridotitas en el monte «Sierra Blanca y Bermeja» del ayuntamiento de Igualeja. Foto: autor.

En el Catálogo de Montes Públicos de 1862 figura el resto de los montes exceptuados de la Desamortización, a favor de cuyos Propios se viene enajenando sus aprovechamientos.

Un caso especial lo constituye el monte «Sierra Bermeja» de Igualeja, que ya figuraba en el Catálogo de los Montes de Utilidad Pública de la provincia exceptuado de la Desamortización de 1862 con el número 66, habiéndose aprobado su deslinde en 1892. En dicho deslinde se le asigna una cabida total de 2.042 has y una pública de 2.018 has. La diferencia entre ambas, de 24 has, es consecuencia del reconocimiento de cuatro enclavados entre los que destaca la Sierra del Algarce con 12 has. Sin embargo, a inicios del siglo XX, en el Catálogo de los Montes de Utilidad Pública de esta provincia elaborado en 1901, dicho monte se adhiere al de Sierra Blanca de Igualeja bajo el nombre de «Sierra Blanca y Bermeja» constituyendo uno sólo. La nueva numeración será el 46.

Por su parte, el deslinde del monte «Sierra Bermeja» de Jubrique fue aprobado en 1912, asignándole una cabida pública y total de 1.101 has.

Muchos de estos espacios han quedado reducidos a pastizales cuyo uso ha estado regulado por los respectivos Ayuntamientos, quienes suelen arrendar al mejor postor los aprovechamientos de los mismos. En la actualidad todos los montes de los Ayuntamientos se encuentran consorciados o conveniados a excepción de «Lomas y Ferreiras», el más pequeño de todos, que ha sido desconsorciado. 


\subsection{Montes consorciados y conveniados}

Los montes de los Ayuntamientos y organismos públicos —en este caso la Tesorería de la Seguridad Social - así como determinados propietarios privados de montes, mantienen en estos momentos algún tipo de consorcio o convenio con la Administración Forestal de cara a conseguir un mayor nivel de preservación. La imposibilidad de afrontar por cuenta propia el conjunto de acciones relativas a la preservación de zonas de alto nivel ecológico amenazadas por procesos erosivos, obliga a consorciar o conveniar tales propiedades con el Estado o la Junta, quienes pasan a ejercer el dominio sobre tales superficies aunque no dispongan de la propiedad de las mismas.

Estos contratos afectan a la mayor parte de los montes públicos de Sierra Bermeja, una superficie montuosa de considerable extensión que delimita principalmente a la foresta sobre peridotitas. Aquí se encuentran los montes de los Ayuntamientos consorciados o conveniados de Estepona, Casares, Genalguacil, Jubrique, Igualeja y Parauta. En el caso de la Sierra del Real, propiedad de la Tesorería de la Seguridad Social, está consorciado con la Junta de Andalucía. La relación que se establece entre Estado y Ayuntamientos afecta a aquellas porciones del monte con unas pendientes más elevadas, donde los incendios y los procesos erosivos son difícilmente controlables si no se actúa sobre ellos con los medios técnicos más adecuados y la celeridad que demandan las circunstancias.

En otros casos, las superficies objeto de contrato son mucho más reducidas, como sucede en la Dehesa de Alcuzcuz. Aunque se trata de un monte particular, no está desconsorciado a pesar de que la Administración no invierte en él desde hace más de quince años. En realidad este monte mantiene un consorcio un tanto especial y además parte de él ha sido urbanizado tras ser calificado como suelo urbano en el PGOU de Benahavis aprobado en el año 1997, por lo que ha perdido su carácter de monte. Este caso es un ejemplo más de cómo los intereses urbanísticos prevalecen sobre los intereses medioambientales en la Costa del Sol, de hecho, es tanta la presión ejercida sobre el suelo de esta zona que se puso en marcha la «Cláusula de la Costa del Sol», por la que los montes públicos podían ser desconsorciados cuando fuera necesario para utilizarlos en beneficio de la actividad económica imperante, la construcción ligada al turismo ${ }^{3}$.

En general, y exceptuando aquellos casos de mala gestión del patrimonio forestal, la intervención estatal consiste generalmente en la regeneración de la cubierta vegetal y en la realización de determinadas obras de contención sobre aquellos suelos más amenazados por los desprendimientos. De igual modo se corrige el cauce de algunos cursos fluviales especialmente peligrosos para las poblaciones que habitan en sus cuencas. En definitiva son actuaciones que intentan garantizar la estabilidad de los ecosistemas, por lo que deben ser contempladas con el máximo interés.

\subsection{Montes particulares}

Los montes de propiedad privada adquieren un importante grado de notoriedad en Sierra Bermeja, ya que suponen más de la mitad de la superficie forestal de la misma, al igual que ocurre en Sierra Crestellina. La mayor parte de ésta se concentra en el municipio de Benahavís, si bien su significación relativa llega a ser importante también en Estepona, Casares, Genalguacil, Jubrique, Faraján, Júzcar, Istán y Pujerra. Estas propiedades pueden

3 La recalificación del suelo de la «Dehesa de Alcuzcuz» se ha realizado a efectos de grandes intereses económicos derivados de la especulación urbanística, por lo que este caso escapa de las explicaciones convencionales otorgadas por la Consejería de Medio Ambiente, así al menos nos lo han dado a entender. 
aparecer como enclavados, tal y como ocurre en Istán dentro del monte del Estado «Sierra del Real». El mayor de estos enclavados es el denominado Hoyo del Bote, si bien existen otros menores también en este monte como El Corchadillo, La Esplanilla, El Balatín, El Pozuelo, etc. En el Monte de Estepona hay dos enclavados, destacando Los Altabacales, con 30 has. También los hay en Sierra Bermeja de Igualeja, donde suponen un total de 24 has.

En general, estamos en presencia de terrenos con una clara vocación forestal, pero muchos de ellos se encuentran destinados en estos momentos a otro tipo de usos. Nuestro conocimiento directo del terreno nos permite afirmar que se reproducen por igual usos agrícolas, forestales y urbanos, estos últimos concentrados en el piedemonte meridional de la Sierra.

Respecto a las superficies montuosas arboladas, hay que señalar la presencia de varias propiedades de considerable extensión y máxima preponderancia ecológica como son el «Monte del Duque» en Casares, y «La Resinera» y «La Máquina» en Benahavís. «La Resinera» constituye la propiedad privada más extensa de Sierra Bermeja con unas 7.000 has aproximadamente. El «Monte del Duque» y «La Máquina» le siguen con alrededor de 2.000 has cada una. El estado de conservación de estas fincas es muy desigual, por una parte, el Monte del Duque destaca por presentar un estado de conservación perfectamente equiparable o superior al que presentan algunos montes públicos. Por otra parte, la dejadez y el desinterés son la tónica general de las otras grandes fincas. Son fincas procedentes de la Desamortización decimonónica o de donaciones reales anteriores a la misma, que han

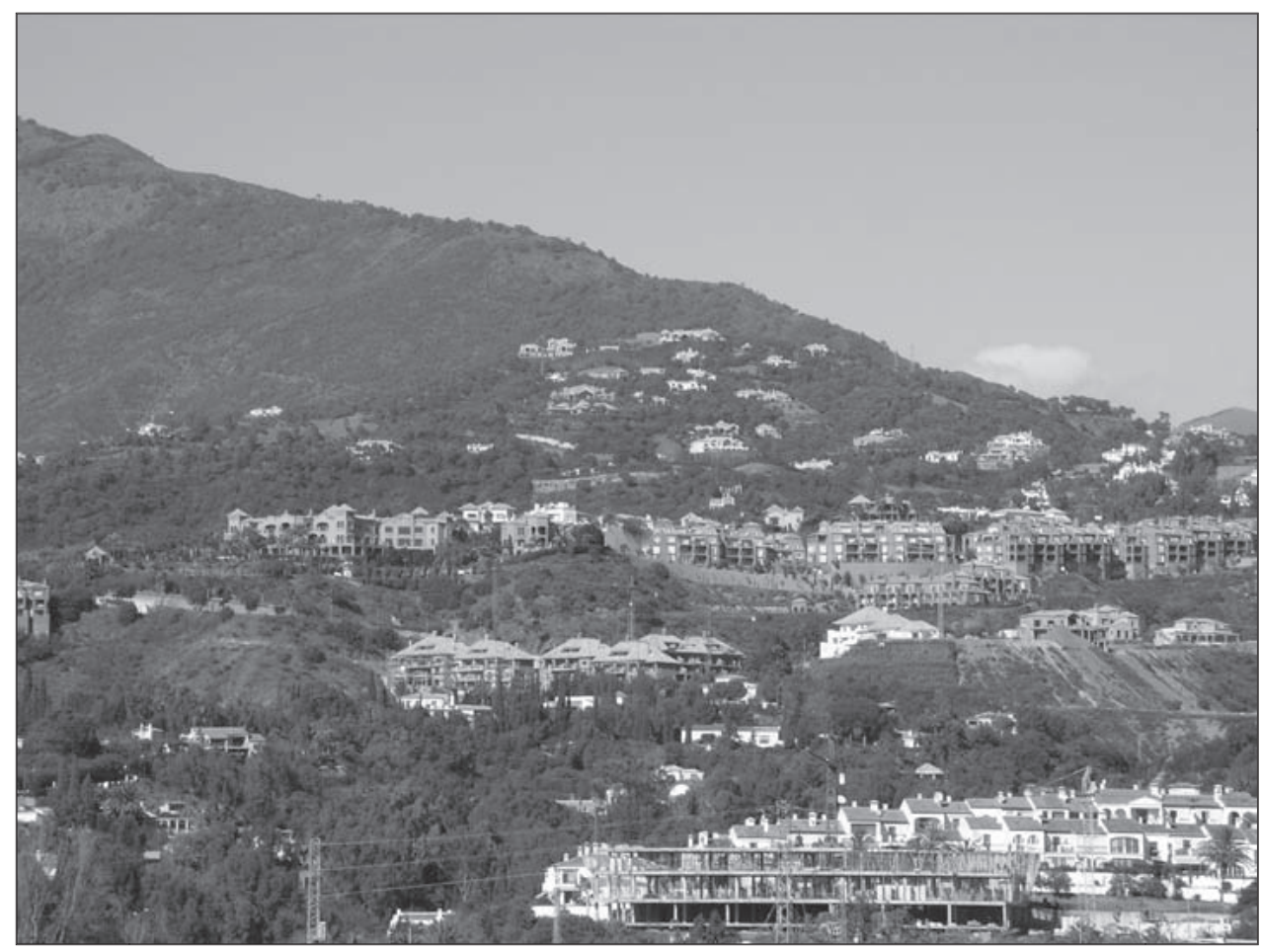

FIgURA 3. Proliferación de urbanizaciones y destrucción del alcornocal-quejigal en «La Zagaleta», Benahavís. Foto: autor. 
ido transmitiéndose de generación en generación sin que el Estado haya podido hacerse con su control. La utilización que se hace de estos predios es semejante a la que se realiza en los montes públicos colindantes, estando su explotación supervisada por la Administración forestal a fin de conseguir el máximo nivel de racionalidad en la gestión del territorio.

Por otro lado, en el resto de las propiedades particulares nos encontramos con un tipo de aprovechamiento muy distinto a los anteriores, ya que las fincas presentan un grado de cobertura arbórea mucho menor y tienen una utilización asociada más a la agricultura y a la ganadería que a la producción maderera. En el caso del Valle del Genal predomina la arboricultura mezclada con aprovechamientos forestales secundarios (saca de corcho, etc.), mientras que en los terrenos de la fachada meridional de Sierra Bermeja, sometidos a un manejo que les ha conducido a una situación muy diferente, predominan los matorrales con aprovechamiento ganadero, exceptuando algunas fincas como «Nicola» (Estepona) o «La Zagaleta» (Benahavís), que presentan una cubierta vegetal predominantemente arbórea compuesta por alcornoques y quejigos. Estos terrenos están sometidos en la actualidad a fuertes presiones derivadas de la especulación urbanística del suelo y en algunos casos como «La Zagaleta» se ha obviado su alta significación ecológica tras ser calificada como suelo urbanizable en el Plan General de Ordenación Urbana del municipio de Benahavís (Fig. 3).

Entre las actividades tradicionales, el aprovechamiento más lucrativo que se obtiene hoy en los montes particulares es el de la madera de pino insigne, que alcanza un buen precio en el mercado comarcal debido a su gran utilidad en múltiples labores de carpintería.

Por otra parte, en la orla esquistosa de Sierra Bermeja, la integración entre ganadería y bosque a través de la montanera, favorecida por la alta pluviometría, se ha traducido en la pervivencia de la vegetación clímax de frondosas (alcornoques, quejigos y encinas) así como de la serie correspondiente a la degradación de ésta en forma de mosaico entre arbolado disperso y matorral-pastizal. Esta montanera no ha sido factible nunca en la escarpada Sierra Crestellina (mármoles), ni sobre las peridotitas, donde la vegetación natural de Pinus pinaster impide este aprovechamiento.

\section{Los montes en la historia}

Los montes públicos presentan un grado de cobertura arbórea aceptable que los hace sumamente apetitosos desde el punto de vista económico y muy apreciados ecológicamente, ya que en su interior es posible encontrar, además, restos de formaciones vegetales autóctonas que no han sucumbido ante el manejo histórico a que se han visto sometidos por parte del hombre.

El interés secular por estos montes viene otorgado por la elevada productividad potencial de los mismos. Por ello, han sido objeto de atención preferente del poder público al menos desde la Edad Media por parte de la Marina. Ya a finales del el siglo XIX se produjo un cambio de actitud del Estado respecto a los montes de Sierra Bermeja, y dejaron de ser valorados desde una óptica meramente productivista para reconocerse en ellos la importante función protectora que ejercían sobre el conjunto de la sociedad, tal y como pondrán de manifiesto algunas catástrofes naturales provocadas por las lluvias torrenciales sobre los suelos desnudos de la Sierra (Gómez Zotano, 2004).

Al amparo de una acumulada experiencia científica en la explotación de los bosques durante la primera mitad del siglo XX, esta potencialidad no ha pasado desapercibida en la actualidad, siendo a partir de la Guerra Civil cuando de nuevo cobraron fuerza los aspectos estratégicos implicados en la explotación de estos predios, aunque desde unas perspectiva totalmente diferentes a las de siglos anteriores, tal y como ha ocurrido con La Resinera. 
A partir de los años sesenta, se tomó una postura diferente que trató de compatibilizar las tres funciones fundamentales que algunos autores como Márquez Fernández (1986), han reconocido en los ámbitos de montaña peninsulares: productivas, protectoras y recreacionales. La primera de estas funciones es especialmente trascendente en Sierra Bermeja, esencialmente por ser una de las principales zonas madereras peninsulares. En cuanto a la función protectora, cabe destacar entre otros aspectos el importante papel medioambiental que la misma desempeña como cabecera hidrográfica de los ríos que vierten a la Costa del Sol, aunque no se reconozca explícitamente en la normativa vigente. Menor peso específico presenta la función recreativa, mucho más desarrollada en el litoral y en los cercanos macizos montañosos de la Sierra de las Nieves, Sierra de Grazalema y Los Alcornocales. Esta última función empieza a ser incipiente en el Valle del Genal.

Los montes públicos y también los privados, han tenido y tienen, por tanto, un considerable interés e importancia en la explicación de muchos de los principales rasgos definidores del paisaje actual del traspaís montañoso de la costa malagueña, así como en el equilibrio ecológico de sus sistemas. Los montes también se han configurado como uno de los principales basamentos en el desarrollo rural de estas montañas mediterráneas. En este sentido, durante el siglo XX se han adaptado importantes decisiones que afectan al conjunto de los montes comarcales y de una forma especial a los predios de titularidad pública. Estas decisiones han sido cruciales en la actual configuración del paisaje de Sierra Bermeja, Sierra Crestellina y, en general, según Rodríguez Martínez (1979), de toda la montaña andaluza.

\section{La ordenación reciente de los montes y los aprovechamientos de Sierra Bermeja y Sierra Crestellina}

Como ya hemos adelantado, el uso forestal de los montes públicos de Sierra Bermeja se puede considerar como el aprovechamiento más importante de todos los vinculados a estos predios. Tal ha sido la importancia de la explotación de la madera, especialmente de pinos, que se llegó a formalizar la figura de los «patilleros», personas que recogían las ramas de los pinos o «patillas». En la actualidad se han dejado de lado estas actividades pero continúan las cortas y en parte de sus montes se han llevado a cabo fructíferas plantaciones forestales que han sorprendido por su buenos resultados, tal y como veremos más adelante.

Entre todas las actuaciones forestales, las repoblaciones constituyen, a nuestro parecer, una de las que mayor incidencia ambiental y paisajística tienen, tanto por la introducción de especies donde no las había antes, ya sean autóctonas o alóctonas, como por las técnicas llevadas a cabo para tal fin que en muchos casos suponen un fuerte impacto al medio.

Tanto en Sierra Bermeja como en Sierra Crestellina, la política de repoblación forestal ha tenido una desigual incidencia en unos y otros montes públicos, tal y como podemos apreciar en la figura 4.

Observando el mapa de la figura 4, destaca en primer lugar la preponderancia de la superficie repoblada respecto al resto de las ocupaciones del monte. En muchos casos, se han repoblado montes prácticamente en su totalidad pero con diferentes especies. En el caso de «El Meliche», durante los años 60 y 70 se llevaron a cabo repoblaciones aterrazadas de eucaliptos, pinos insignes y pinos resineros. Lo mismo ocurrió en los pequeños predios ubicados en Faraján, Júzcar, Pujerra y Jubrique, donde se abancalaron las laderas gnéisicas en torno al Cerro Jardón para realizar plantaciones homogéneas de pino insigne. En el monte de Sierra Crestellina de Casares la especie introducida fue el pino carrasco fundamentalmente (Fig. 5), mientras que en el resto de montes de Sierra Bermeja, y siempre sobre sustrato ultramáfico, se repobló con pino resinero usando tanto técnicas blandas como 


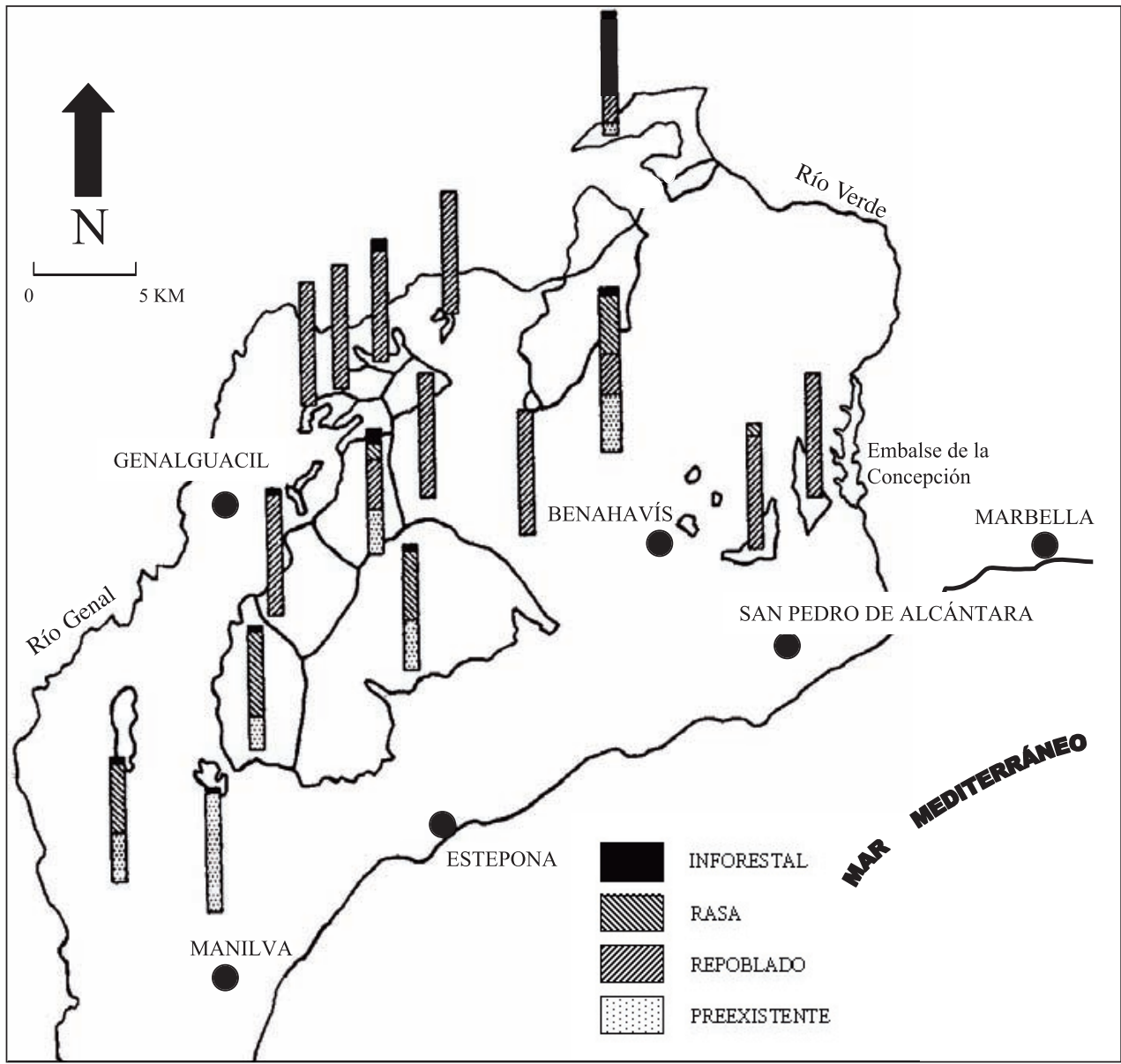

Figura 4. Mapa de repoblaciones efectuadas desde 1940 a 1979.

Fuente: Garzón Blanco (1999). Elaboración propia.

duras. Entre estos últimos predios repoblados destaca por su volumen Sierra Bermeja de Genalguacil, y por los aterrazamientos efectuados El Pinar de Casares y Sierra Bermeja de Estepona. En este último predio, también sobre peridotitas, se crearon bosquetes de eucaliptos como el de los Bajos de Peñas Blancas.

En cuanto a la superficie forestal preexistente, cabe destacar la dehesa de Las Acedías, en Casares, donde se preservaba el bosque de alcornoques. En el resto de montes, la superficie arbolada preexistente a las intervenciones forestales del periodo señalado era prácticamente nula a excepción de Sierra Crestellina, El Pinar y Sierra Bermeja de Estepona, de Jubrique y de Igualeja. El amplio porcentaje de superficie rasa que aparece en este último monte se debe a la inclusión en el mismo de Sierra Blanca de Igualeja. En este sentido cabe destacar también la superficie inforestal de los Montes de Parauta, correspondiente a los materiales carbonatados de la Sierra de las Nieves. 


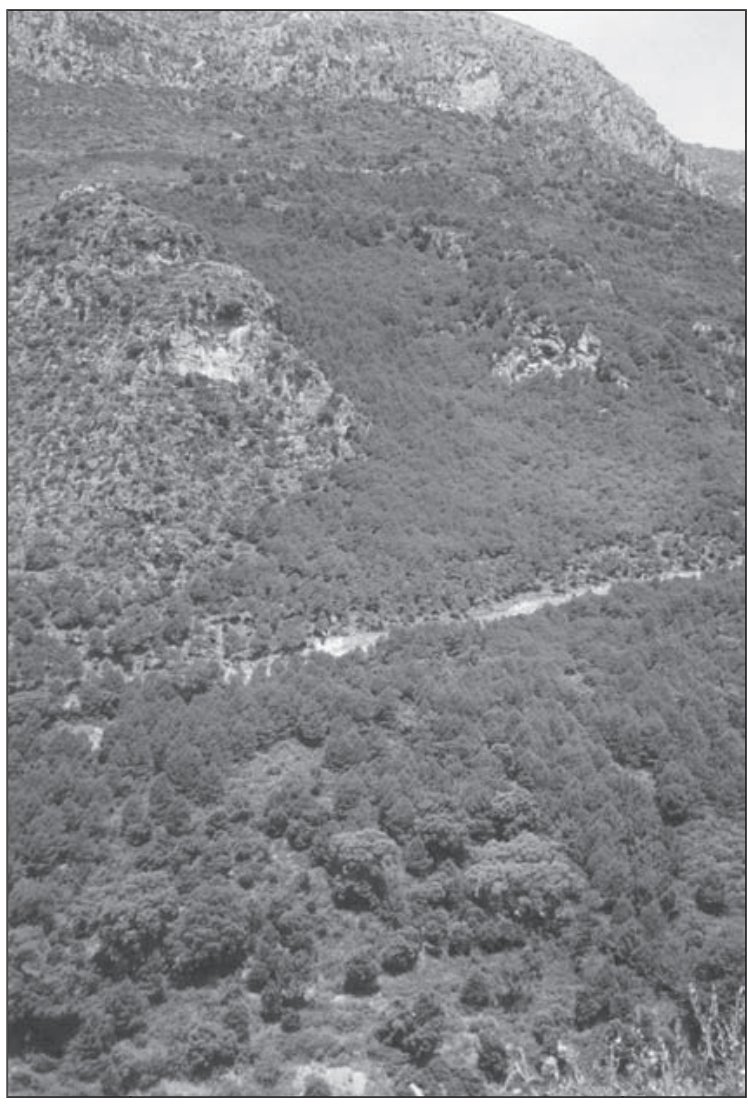

FIgURA 5. Repoblación de pinos efectuada en Sierra Crestellina. Foto: autor.

Ya en la actualidad, se han llevado a cabo otra serie de repoblaciones forestales cuyo fin último no es meramente productivísta sino medioambiental. Entre las últimas repoblaciones destacamos las realizadas con pinsapos (Abies pinsapo) en el cerro Abanto (Montes de Parauta) al amparo del Parque Natural de la Sierra de las Nieves, y en el cerro Porrejón (Genalguacil y Jubrique), con el fin de reintroducir el pinsapar en su área potencial. La buena respuesta que han dado los plantones ha permitido la continuación de las repoblaciones en este último paraje con la creación de un nuevo rodal de unas 14 has en la umbría del mismo (Jubrique).

Otras repoblaciones con Abies pinsapo alternando con Pinus pinaster se están efectuando con desiguales resultados en las zonas desarboladas de la Sierra del Real tras el incendio ocurrido en 1991.

El panorama de las repoblaciones se completa con la reintroducción de alcornoques en los Hoyos de Calonga (Sierra Bermeja de Estepona) y la repoblación de Pinus pinaster en El Pinar de Casares. En general, todas estas repoblaciones no suponen un impacto negativo al medio, pues en ellas se alterna la técnica del hoyo manual con el aprovechamiento de las terrazas ya realizadas con anterioridad en otras repoblaciones infructuosas como las del Pinar de Casares. 
De las facilidades e inconvenientes para repoblar Sierra Bermeja nos habla GómezGuillamón (1967): «Puede observarse, que en conjunto, el estado del repoblado joven es bastante mejor de lo que podía esperase. Esto es debido a la gran afinidad que presentan estos terrenos peridotíticos para la repoblación natural o artificial con pino pinaster. Por otra parte, las plantitas jóvenes parece que, en todo el macizo de Sierra Bermeja, no son muy exigentes en cuanto protección de árboles adultos, siendo en cambio muy difícil que el repoblado se produzca en abundancia en rodales bien poblados. Incluso en rodales prácticamente rasos, se puede encontrar repoblado abundante, con tal de que a $200 \mathrm{o}$ 300 metros de distancia existan árboles padres. Es claro, que en este último caso, la repoblación ha debido conseguirse muy lentamente, pues la densidad de diseminado anual no ha podido ser grande.

Se comprueba también esta poca exigencia en sombra del repoblado, cuando inmediatamente después de quedar arrasado por un incendio el vuelo arbóreo, aparece rápidamente un repoblado muy abundante, que debe provenir de la semilla que existía en el suelo antes del incendio, porque si, como por desgracia ha ocurrido algunas veces, un nuevo incendio destruye las pinpolladas que aún no han dado fruto, el repoblado ya no surge nuevamente con rapidez, y queda condicionada su producción a la existencia de árboles padres a las distancias que antes hemos dicho» ${ }^{4}$.

Como podemos comprobar, «...dada la gran afinidad del P. pinaster por las peridotitas, no existe prácticamente, problema de repoblación natural. Tan solo debe cuidarse la cuestión del ganado, acotando aquellos tramos en los que la repoblación sea menos abundante. La experiencia acumulada en los montes vecinos de la Sierra Bermeja: Estepona, Genalguacil, Casares y Jubrique, y en el propio Igualeja, en los dos planes quinquenales de su Ordenación Provisional, nos lleva a reafirmarnos en lo dicho: Basta con acotar para repoblar. Es más, independientemente del diente del ganado, se ha comprobado que el único factor limitativo de la repoblación natural es, en resumidas cuentas, la falta de luz constante al estado de espesura» ${ }^{5}$.

Respecto a las necesarias acotaciones a que hace alusión Gómez-Guillamón, éstas continúan siendo imprescindibles para preservar las repoblaciones ante el continuo asedio del ganado, especialmente en los pinsapares. Tanto el pinsapar del Cerro Abanto como la parte alta del pinsapar de Los Reales han sido alambrados. En el monte Sierra del Real también se ha realizado un cerramiento del pinsapar de Armas que tiene una longitud de $6.000 \mathrm{~m}$. La finalidad principal de estos cercados consiste en evitar la entrada a animales dañinos para la regeneración del pinsapar como es el caso de las cabras domésticas, los cerdos y las cabras monteses.

Junto a las repoblaciones destacamos los tratamientos preventivos, que consisten principalmente en la realización de cortafuegos y de fajas auxiliares (en torno a los caminos), y el arreglo de caminos, obras de fábrica y otras infraestructuras necesarias para la conservación y mantenimiento de este tipo de predios.

Entre los tratamientos silvícolas destacamos la entresaca de especies foráneas introducidas en El Meliche durante los años 60 y 70 (Eucaliptus y Pinus radiata), que pretende dar luz a los manchones de alcornoques que están saliendo con fuerza. Con la misma finalidad resaltamos también el aclareo del pinar del cerro del Majuelo, en Sierra Bermeja de Estepona.

Otro de los tratamientos silvícolas importantes en estos montes es la limpieza y aclareo de las masas forestales, una actuación imprescindible para la conservación de los bosques

\footnotetext{
4 Gómez-Guillamón (1967): Proyecto de Ordenación del monte «Sierra Blanca y Bermeja». Pág. 70.

5 Gómez-Guillamón (1967): Proyecto de Ordenación del monte «Sierra Blanca y Bermeja». Capítulo Segundo, pág. 25.
} 
frente a los incendios. En este sentido, destacamos por ejemplo la intervención llevada a cabo recientemente en el pinar de pinus halepensis de Sierra Crestellina, masa que contaba con un espesor excesivo de 5.000 pies/ha, y el desbroce previo al descorche de los alcornoques de todo el monte de Las Acedías.

Frente al uso forestal de los montes, otros aprovechamientos como el ganadero y el cinegético pueden resultar igualmente impactantes en este territorio, especialmente el primero.

El aprovechamiento ganadero está protagonizado por el ganado ovino, caprino, caballar y de cerda. Cuando éste es reglado, resulta poco impactante, pero cuando se convierte en pastoreo furtivo - normalmente abusivo - sus efectos se vuelven muy nocivos para la regeneración vegetal, especialmente para los cumbreños bosques de pinsapo, donde los animales encuentran refugio en los calurosos meses del verano. Estos frágiles bosques quedan desprotegidos del diente del ganado caprino y sus suelos quedan totalmente removidos al convertirse el pinsapar en hozadero de puercos y jabalíes, tal y como ocurre en Los Reales de Sierra Bermeja o el en pinsapar de la Sierra del Real, impidiendo la germinación de nuevas semillas y facilitando la erosión del suelo.

Las infracciones cometidas contra los montes públicos por el pastoreo abusivo son una asignatura pendiente en los montes de Sierra Bermeja. Ya en los años 60 del siglo XX, y sólo en el monte «Sierra Blanca y Bermeja» de Igualeja se registraron al efecto 224 denuncias entre los años 1960 y 1967.

En cuanto al aprovechamiento cinegético, resulta ser inviable para el medio cuando se sobrecarga la capacidad de acogida del mismo respecto a las especies valoradas para la caza, caso de la cabra montes y su repercusión en la vegetación de las cumbres de Sierra Bermeja, especialmente y, de nuevo, sobre la valiosa flora asociada al pinsapar.

\section{La quiebra del sistema tradicional de aprovechamientos del monte frente a las nuevas funciones}

Durante la década de los sesenta y setenta del siglo pasado se registra en España un crecimiento económico que traerá consigo, entre otras muchas cosas, un enorme incremento de los espacios naturales protegidos. No obstante, en Sierra Bermeja, en función de su ubicación, se dará prioridad a otra de las actividades más demandadas, el turismo. La promoción de estas nuevas actividades relacionadas con el turismo podría contribuir a paliar el vacío creado por la crisis de los aprovechamientos tradicionales del monte si no fuera porque no se han insertado dentro de unas coordenadas de respeto al medio natural y en consonancia con las peculiaridades de las poblaciones que aún permanecen vinculadas a este territorio. Nada más lejos de la propuesta de Rodríguez Martínez (1985), que sugiere para áreas afines a la nuestra, partir de una estructuración conveniente de los nuevos aprovechamientos que compatibilice la obtención de rentas, con la preservación de los recursos naturales existentes en ellas, ambas tan necesarias para zonas tan deprimidas como la montaña andaluza.

En estos momentos asistimos al resurgir de algunos usos que habían permanecido en segundo plano y que las nuevas funciones de la sociedad moderna demandan de los montes. Junto a la madera, y en menor importancia los pastos, que siguen siendo unos aprovechamientos de los que se saca una buena rentabilidad económica, se ha producido un incremento de los ingresos producidos por actividades como la caza o la pesca. Otras actividades como la extracción de áridos, la apicultura o la instalación de infraestructura turística también proporcionan rentas de consideración que demuestran esos cambios que se están operando en el uso tradicional de estos espacios. 
Como podemos apreciar en las tablas correspondientes a las caracterizaciones económicas de los montes de propios para los años 1985 y 2003 (Tablas 4 y 5), la continuidad de las actividades forestales, el incremento de la actividad cinegética y el descenso de los aprovechamientos ganaderos son, junto con la práctica desaparición de las actividades secundarias, las claves de la quiebra del sistema tradicional de aprovechamientos del monte frente a las nuevas funciones. Prueba de ello es que han dejado de realizarse infracciones contra los montes públicos y ya prácticamente no aparecen denuncias por corta de árboles, desrrames, roturaciones, extracción de frutos, resinaciones o descortezamiento.

Tabla 4

CARACTERIZACIÓN ECONÓMICA DE LOS APROVECHAMIENTOS PREVISTOS PARA LOS MONTES DE PROPIOS DE SIERRA BERMEJA (1985) (PTAS.)

\begin{tabular}{|l|c|c|c|c|c|c|c|}
\hline MUNICIPIOS & MADERA & PASTOS & CAZA & ESPARTO & PALMITOS & $\begin{array}{c}\text { HIERBAS AROMÁ- } \\
\text { TICAS }\end{array}$ & ÁRIDOS \\
\hline Casares & - & 24.250 & 39.286 & 16.714 & 30.000 & - & - \\
\hline Estepona & - & 345.900 & 120.000 & - & - & - & - \\
\hline Genalguacil & 447.500 & - & 2.000 & - & - & - & - \\
\hline Igualeja* & - & 45.786 & 150.000 & 17.500 & - & 1.000 & 792.176 \\
\hline Jubrique & 1.442 .500 & - & - & - & - & - & - \\
\hline Parauta & - & 20.000 & - & - & - & - & - \\
\hline TOTAL & 1.890 .000 & 435.936 & 311.286 & 34.214 & 30.000 & 1.000 & 792.176 \\
\hline
\end{tabular}

* El caso de Igualeja induce a error, ya que tanto el aprovechamiento de las hierbas aromáticas como de los áridos se realiza sobre Sierra Blanca y no en Sierra Bermeja.

Fuente: Gómez Moreno (1987).

Tabla 5

CARACTERIZACIÓN ECONÓMICA ESTIMADA DE LOS APROVECHAMIENTOS PREVISTOS PARA LOS MONTES DE PROPIOS (2003) (€)

\begin{tabular}{|l|c|c|c|c|c|c|c|}
\hline \multicolumn{1}{|c|}{ MUNICIPIOS } & MADERA & PASTOS & CAZA & ESPARTO & PALMITOS & $\begin{array}{c}\text { HIERBAS } \\
\text { AROMÁTICAS }\end{array}$ & ÁRIDOS \\
\hline Casares & - & $1.378,08$ & $2.060,27$ & - & - & - & - \\
\hline Estepona & $6.971,6$ & 1.290 & $9.112,54$ & - & - & - & - \\
\hline Genalguacil & $6.971,6$ & 519,26 & $1.818,51$ & - & - & - & - \\
\hline Igualeja & $13.943,2$ & $11.982,9$ & $6.971,13$ & - & - & - & - \\
\hline Jubrique & $8.674,4$ & $2.271,8$ & $3.143,14$ & - & - & - & - \\
\hline Parauta & 139,2 & 63,08 & - & - & - & - & - \\
\hline TOTAL & 36.700 & $17.505,59$ & $23.105,6$ & - & - & - & - \\
\hline
\end{tabular}

Fuente: «Planes anuales de aprovechamientos».

La madera resulta ser el aprovechamiento más remunerativo, tal y como ha venido ocurriendo a lo largo de los siglos en Sierra Bermeja. Estas cifras hay que tomarlas con 


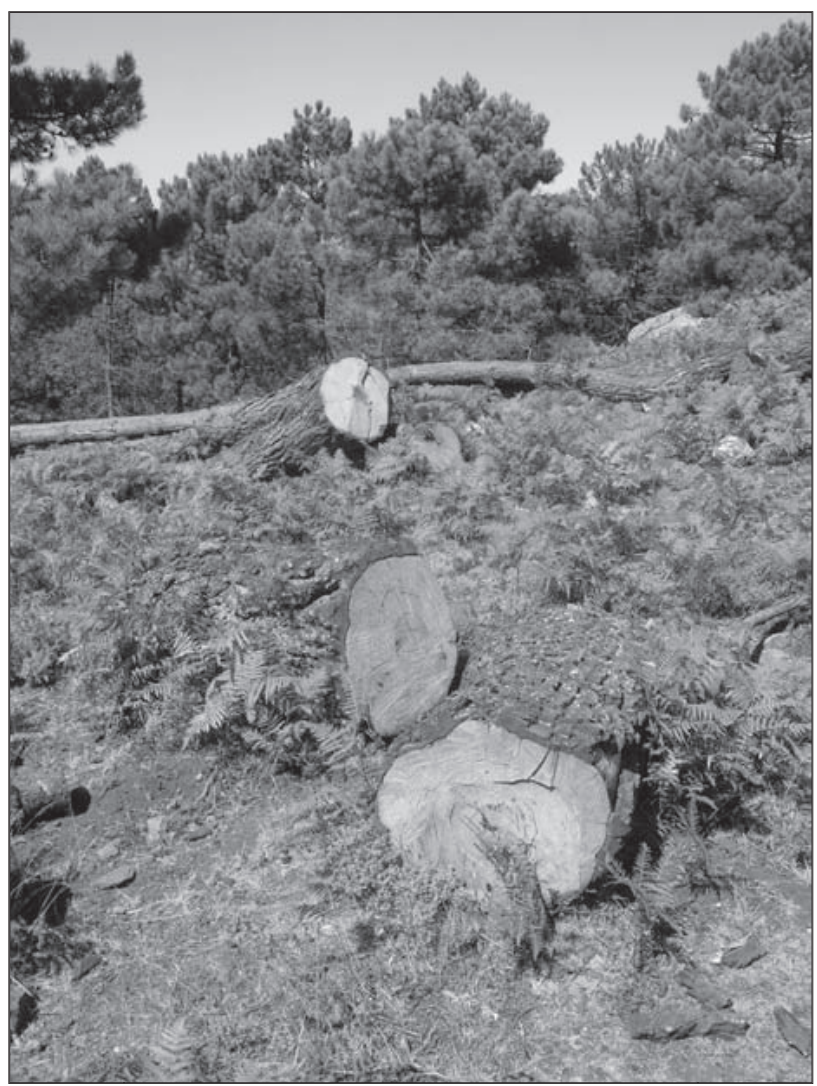

Figura 6. Aprovechamiento maderero en el monte público de Igualeja. Foto: autor.

precaución, pues no todos los años se establecen las mismas estimaciones y, estas pueden variar de un año a otro sustancialmente. Por esta razón hemos de tomar estos datos como una aproximación, pero igualmente válida para nuestros objetivos. De esta manera vemos como en 1985 eran los predios de Jubrique y Genalguacil los únicos que habían estimado realizar un aprovechamiento de la madera de los pinares, mientras que en el 2003 coinciden la mayor parte de los montes, destacando Sierra Bermeja de Igualeja donde se están cortando los pinos ubicados en los alrededores de la Fuenfría Alta y la cabecera del río Seco (Fig. 6).

Estos aprovechamientos se consideran compatibles con la producción de otros bienes y servicios que genera el monte como son la protección, los pastos y el uso social y recreativo. En este sentido, son muchos los autores que como Jiménez Martín (2000), apuestan por mantener unas densidades óptimas para la producción maderera que redundaría en la mejora del estado de la masa con respecto al riesgo de incendios. Según el Proyecto de Ordenación del monte de Jubrique, el mayor productor de madera, esta procede tanto de las cortas de regeneración, como de las claras, siendo la primera las dos terceras partes del total aproximadamente (Jiménez Martín, 2000).

Sin embargo, en la actualidad asistimos a una profunda transformación de los métodos tradicionales de obtención de la riqueza forestal. La mecanización de las actividades fores- 
tales ha supuesto uno de los grandes revulsivos en el cambio del paisaje de Sierra Bermeja, basta con observar los aterrazamientos efectuados para las repoblaciones forestales de pino insigne (Pinus radiata) en la medianería de esta montaña.

Como ya hemos comentado anteriormente, a comienzos de los años sesenta, el recién creado Instituto Nacional para la Conservación de la Naturaleza tomó la iniciativa en la implantación de un nuevo uso en Sierra Bermeja. De acuerdo con Gómez Moreno (1987), tanto por la degradación medioambiental (zonas deforestadas y con sobrepastoreo), como por el éxodo rural, bajo la acción institucional, se ha sustituido el tradicional sistema de explotación silvopastoril por otro de monoexplotación forestal. Este es el caso de las extensas plantaciones de pino insigne en la medianería gnéisica en torno al Cerro Jardón con fines meramente productivistas. El éxito de estas explotaciones forestales ha sido tal que actualmente existe más demanda que oferta de madera, por lo que en estos años se han realizado numerosas cortas finales en montes consorciados, en muchos de los cuales no se está repoblando (Fig. 7). Esto ha planteado una situación problemática a las empresas madereras locales en cuanto a abastecimiento de madera en un futuro inmediato y que puede tener graves repercusiones en los bosques naturales de resinosas de la Sierra. Las empresas principales que actúan en esta zona son la Maderera de Benarrabá y la Cooperativa Maderera del Genal, que demandan fustes para la fabricación de cajas y palets principalmente. Los pies más gruesos se reservan para encargos de vigas de construcción. Además existen otras empresas madereras en los pueblos cercanos de Ronda y Jimena de la Frontera, en este último se ubica la empresa más competitiva denominada Aguilar Forestal S.L.

En cuanto a los pastos, las limitaciones de la presencia de la ganadería en los montes es otra de las repercusiones de la nueva política forestal que poco a poco va dejándose sentir en Sierra Bermeja, aunque no con la intensidad de otras sierras como la de Grazalema o la de Segura.

Además, en los municipios costeros, completamente polarizados por la función económica terciaria de la Costa del Sol, la ganadería existente se concentra en los montes públicos debido a los precios más favorables de estas tierras respecto a las privadas, que están sometidas a la especulación derivada de su emplazamiento periurbano. En estos ayuntamientos se concentran las subastas declaradas desiertas. Por esta razón, han pasado de ser la segunda fuente de ingresos en general en 1985, a ser la tercera en la actualidad para todos los montes ubicados en Sierra Bermeja y Sierra Crestellina. Este retroceso ha sido especialmente significativo en el monte de Estepona, donde los continuados incendios forestales han mermado considerablemente la capacidad de carga ganadera del mismo. Todos estos aprovechamientos se llevan a cabo en los montes de Sierra Bermeja, exceptuando el de Casares, ya que dicho término municipal, con una importante actividad ganadera extensiva, posee otras tierras donde la calidad de los pastos es mayor (lomas del Flysch y Sierra Crestellina).

En cuanto a la caza, se está convirtiendo en un aprovechamiento en alza, especialmente la caza mayor, que es la más remunerativa. Sierra Bermeja de Estepona y Sierra Bermeja de Igualeja son los predios que más ingresos alcanzan por tal aprovechamiento. En la mayoría de los montes de Sierra Bermeja existe caza mayor de cabra montés como especie reina que se complementa con caza menor de conejo, perdiz, zorro, paloma torcaz y zorzal entre otras especies. En Sierra Crestellina no se puede cazar desde su declaración como paraje natural.

En la regulación legal y adecuación territorial de las actividades cinegéticas juega un papel decisivo la iniciativa municipal. Recientemente se ha llevado esta posibilidad a casos preocupantes. El 17 de agosto de 2002, la Comisión de Gobierno del Ayuntamiento de Estepona concedió la cesión de usos del monte público de Sierra Bermeja durante 35 


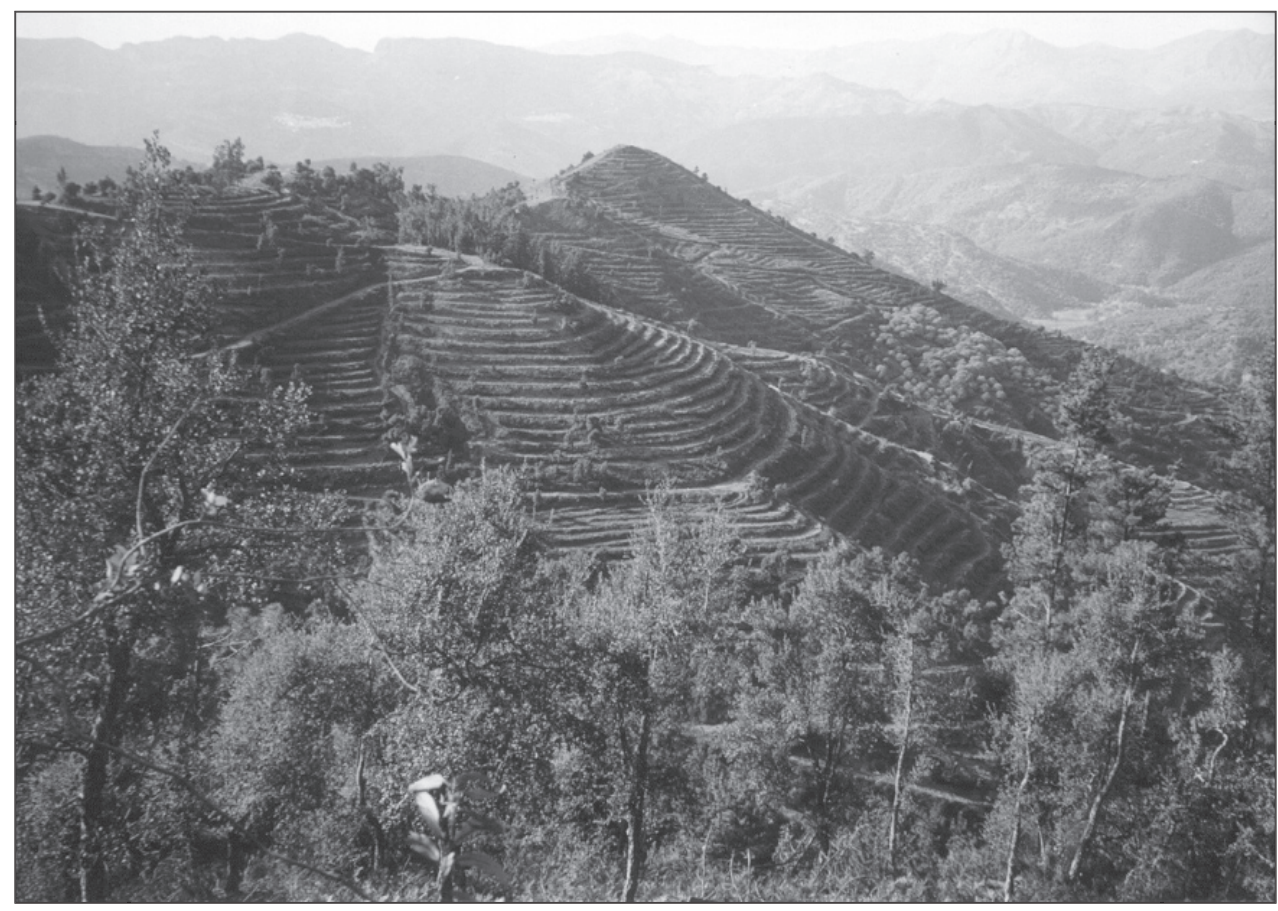

Figura 7. Aterrazamientos descubiertos tras la corta de pinos insignes en el Cerro de los Castillejos. Monte «Lomas y Ferreiras», Júzcar. Foto: autor.

años a la empresa «Sierra Bermeja, S.L», por una cifra irrisoria de 1.200.000 euros, unos 40.000 euros anuales, lo que supone que vende el metro cuadrado a 0,001 céntimos de euro. De acuerdo con la legislación vigente, la cesión por más de 10 años se puede considerar prácticamente una venta.

Según las alegaciones realizadas por la asociación GRUNSBER-Ecologistas en Acción, en relación con la «Propuesta de Ordenación Socio-Recreativa, Cinegética y de Educación Medio Ambiental del Monte Sierra Bermeja, No 23 del Catálogo de los de Utilidad Pública de la provincia de Málaga, en el término municipal de Estepona», la consiguiente cesión de usos de Sierra Bermeja podía resultar gravemente lesivo para la Sierra, ya que se preveían cerramientos de vallados cinegéticos que iban a producir un fuerte efecto barrera en los pasos naturales de las distintas especies propias del macizo que se encuentran, además, protegidas a distintos niveles (nutria, tejón, jineta, gato montés, garduña, meloncillo, etc.), así como a la actividad de las rapaces (azor, águila culebrera, águila calzada, águila perdicera, búho real, halcón, etc.) que usan como cazaderos precisamente las zonas donde se ubican los límites de las áreas y por tanto los vallados, interfiriendo éstos en los vuelos rasantes de persecución de presas. De igual modo, la introducción de especies foráneas como el muflón, el gamo o el ciervo supondrían una sobrecarga de fuerte impacto sobre los suelos y la vegetación natural, así como la expulsión de la cabaña ganadera que tradicionalmente ha mantenido estable el funcionamiento del ecosistema. Estas especies someterían a la vegetación endémica a una presión suficiente como para ponerlas en peligro de extinción. Además, las especies de caza mayor mencionadas, podrían competir estrechamente con especies autóctonas como la cabra montés y el corzo. Igualmente, la introducción de ic- 
tiofauna como la trucha arcoiris en los ríos y arroyos del monte pondrían en serio peligro las poblaciones de nutria, ya que se acondicionarían los mismos para adaptarlos a las condiciones necesarias para la supervivencia de estas especies alóctonas. En definitiva, con este proyecto predominaba la búsqueda de rentabilidad económica sobre la conservación de especies autóctonas y el mantenimiento de sus recursos naturales. Como vemos, el uso complementario de ocio, supondría en este caso una grave alteración de la relativa preservación de las actuales condiciones naturales de este Complejo Serrano No 23.

En cuanto a los aprovechamientos secundarios, caracterizados por el esparto, los palmitos, las hierbas aromáticas y los áridos, asistimos a la paulatina desaparición generalizada de los mismos frente al resurgir de otros. En el caso del aprovechamiento como el esparto, que se habían venido obteniendo secularmente en los montes de Sierra Bermeja, ha sido sustituido en la actualidad por fibras sintéticas. El palmito por su parte, ha dejado de recolectarse en Casares, donde en 1985 suponía uno de los aprovechamientos más remunerativos del ayuntamiento. Similar suerte han corrido las hierbas aromáticas, recogidas principalmente en el monte de Igualeja.

En cambio, otros aprovechamientos tradicionales secundarios como el apícola se encuentran en una relativa alza especialmente en algunos montes de propios como los de Igualeja $(250,56 €)$ o Parauta $(104,4 €)$. Aquellos montes de propios que, como en el caso de Jubrique, albergan en su interior plantaciones de castaños, han estimado su aprovechamiento en unos $125,01 €$.

En cuanto a la explotación de áridos y mármol continúa practicándose en Igualeja y con más intensidad que nunca como respuesta a la demanda de la Costa del Sol, pero la nueva Ley Forestal de Andalucía considera a estos aprovechamientos como una ocupación, por lo que no se han tenido en cuenta a la hora de realizar la caracterización económica del 2003.

Finalmente, cabe hacer mención al corcho, que pese a ser un aprovechamiento carente de importancia en los montes de propios de Sierra Bermeja dada la ausencia de alcornoques, si presenta resultados significativos los montes particulares de la Sierra (Fig. 8). Esto se debe a que el alcornoque se concentra en el piedemonte esquistoso, fuera de los límites de los predios de los ayuntamientos, por lo que su explotación está en manos de particulares. El monte de Las Acedías en Casares era el único que mantenía este tipo de aprovechamiento hasta que quedó recientemente destruido por un incendio forestal. En la caracterización económica de 1985 no queda reflejado su aprovechamiento por no ser un año de sacas.

En cuanto al uso recreativo del monte, en los Proyectos de Ordenación no se prevé un aumento de su demanda, consolidándose ciertas zonas tradicionalmente dedicadas a usos recreacionales en los montes de Jubrique y Genalguacil como el Arroyo del Estercal, el Charco Azul, etc.

Por último, cabe destacar un incremento reciente en la sensibilización sobre la necesidad de proteger los valores naturales de estos montes que se ha materializado en la protección de los espacios naturales y una política medioambiental entre las nuevas funciones del espacio montañoso.

Sierra Bermeja y Sierra Crestellina conservan aún en la actualidad sistemas naturales de elevado valor ecológico pese a presentar un notable deterioro medioambiental resultado de una incesante utilización antrópica a lo largo de la historia.

En este sentido, y pese a la fuerte presión ejercida por los agentes económicos y políticos implicados en el desarrollismo de la zona, (recordemos que su alto valor ecológico se encuentra continuamente amenazado por el importante desarrollo urbano de municipios como Benahavís, Marbella, Estepona o Casares), se ha puesto en marcha una red de espacios naturales protegidos que reconoce los valores naturales de la región, especialmente de su 


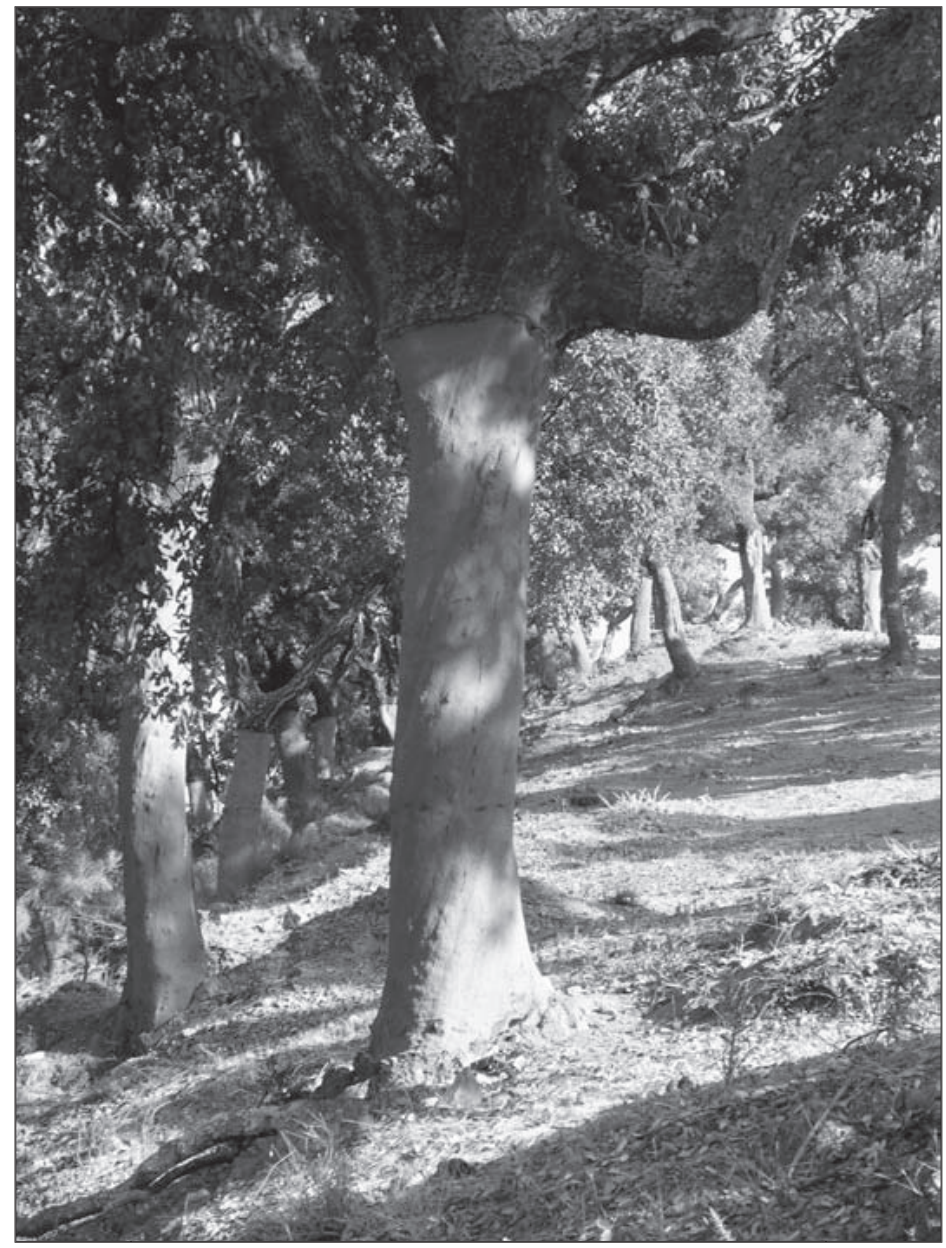

Figura 8. Alcornoques descorchados en El Meliche. Foto: autor.

área montana, pero que adolece de un tratamiento integrado de los sistemas naturales. De esta manera, nos encontramos con una red inconexa de espacios protegidos compuesta por un Parque Natural («Sierra de las Nieves») que afecta a los Montes de Parauta y dos Parajes Naturales, «Sierra Crestellina», que abarca al monte del mismo nombre y «Los Reales de Sierra Bermeja», que comparte las cumbres de los montes de El Pinar de Casares, Sierra Bermeja de Estepota y Sierra Bermeja de Genalguacil. A la tardía implementación de la Red de Espacios Naturales Protegidos de Andalucía se suman otras iniciativas de conservación y protección como la Reserva de la Biosfera de la Sierra de las Nieves, la Reserva Nacional de Caza de la Serranía de Ronda, que se solapan a los Montes de Parauta y Sierra del Real de Istán.

En los últimos años al amparo de la Red Natura 2000 se ha ampliado la protección ambiental de Sierra Bermeja y Sierra Crestellina intentando conectar las diferentes figuras entre sí y con el litoral, así como con otros espacios protegidos del interior de la provincia con el establecimiento de una serie de «corredores naturales». 
Esta preocupación por la conservación del medio no tiene repercusión solamente en el ámbito comunitario. Con el paso de los años, la formulación de una política de protección de la naturaleza más globalizada ha permitido que en un futuro próximo esté prevista la integración de Sierra Bermeja y Sierra Crestellina en una gran Reserva de la Biosfera Intercontinental hispano-marroquí. Es más, sólo el valor de Sierra Bermeja es tal que se está estudiando su posible catalogación como Parque Nacional, ya que sus caracteres exclusivos la hacen ser un espacio natural sin parangón en Europa ni, seguramente, en el mundo.

No obstante, la fragmentación y descoordinación de las políticas medioambientales de esta parte de la Costa del Sol se pone claramente de manifiesto a la hora de proteger áreas de elevado valor ambiental como ocurre en los tres pinsapares de Sierra Bermeja (pinsapar de Los Reales, pinsapar del Cerro Abanto y pinsapar de Armas), únicos en el mundo sobre peridotitas. El primero ostenta una figura de protección específica elaborada para el mismo (Paraje Natural de Los Reales de Sierra Bermeja). El segundo se incluye dentro del límite del Parque Natural de la Sierra de las Nieves, con un nivel de protección máximo, mientras que el tercero, a escasos $9 \mathrm{~km}$ de éste no detenta ninguna protección específica ni tan siquiera en el Plan Especial de Protección del Medio Físico de la provincia de Málaga, que únicamente lo incluye en un amplio Complejo Serrano de Interés Ambiental. Además, la superposición de figuras de planeamiento no implica necesariamente una compensación de niveles de protección a la hora de ordenar ámbitos naturales similares en desigual situación legislativa. Por ejemplo, tanto el pinsapar del Cerro Abanto como el de Armas, incluidos ambos en la Reserva de la Biosfera de la Sierra de las Nieves, tienen diferentes niveles de protección sin tener en cuenta que el segundo de los pinsapares está menos protegido que el primero.

De igual modo, nos encontramos, por un lado, con un paquete de medidas encaminadas a proteger los espacios naturales como respuesta a las nuevas funciones de la montaña, y por el otro, con el planeamiento municipal, llegando a superponerse diversas figuras con fines distintos para el territorio. Teniendo en cuenta el sistema de planificación ambiental que se aplica en la Costa del Sol, podemos hablar de una frontera en litigio entre el espacio litoral desprotegido y su trasfondo montañoso (protegido) (Gómez y Paniza, 2003). Podríamos destacar en este sentido numerosos casos de competencias concurrentes muchas veces contradictorias como por ejemplo la inclusión del Cerro Alcuzcuz dentro del LIC «Sierra Bermeja y Real» por parte de la Red Natura 2000 frente a la actual urbanización del mismo al amparo del PGOU de Benahavís aprobado en 1997.

El panorama real que hemos descrito brevemente en alguno de sus aspectos ambientales, pone de manifiesto la problemática política que supone la ordenación de la montaña ligada al litoral, de Sierra Bermeja y Sierra Crestellina como trasfondo montañoso de la Costa del Sol Occidental. No resulta fácil, pues, intuir cuál será la organización territorial de la Costa del Sol, cuando es precisamente en este territorio donde mejor se manifiestan las interacciones entre los distintos usos y actividades humanas. En este sentido, es importante destacar la falta de madurez del sistema de protección ambiental en la Costa del Sol. No se trata de proteger solo aquel suelo que no es urbanizable, sino también -y aquí radica su efectividad- aquellas zonas de valor que se encuentran realmente en peligro y que son apetecidas por la actividad socioeconómica imperante. Ni siquiera el Plan de Ordenación del Territorio de la Costa del Sol (POT), presentado recientemente, se ha percatado del elevado valor ecológico del lugar y no ha tomado las medidas preventivas oportunas para su protección a la espera de serle otorgada alguna de las figuras que se contemplan en la legislación vigente a tal efecto.

A éste respecto, esperemos que la Red Natura 2000 tenga un valor efectivo en la conservación de la naturaleza para los próximos años, convirtiéndose en un elemento esencial 
para conseguir un desarrollo compatible con la conservación de la naturaleza. La adecuada implantación de la Red europea para la conservación de la naturaleza resulta, en este sentido, especialmente importante en el caso de Sierra Bermeja y su costa, al tratarse de un espacio de elevada biodiversidad. La presencia de numerosos endemismos y su fragilidad ante las actividades generadas en la Costa del Sol orienta la gestión de éste espacio natural a la máxima protección posible en nuestra actual legislación.

\section{Conclusiones}

Es de destacar en primer lugar la importancia superficial que tienen los predios de titularidad pública en Sierra Bermeja, aunque no superior a los de titularidad privada. En segundo lugar, llama la atención como la distribución espacial que figura en el mapa de montes resulta de una combinación de factores medioambientales e históricos. Esta realidad ha sido analizada por Gómez Moreno (1987) para el cómputo de los montes de propios de la provincia de Málaga y evidencia que los linderos de las tierras de propios en Sierra Bermeja y Sierra Crestellina coinciden con la línea de discontinuidad litológica entre tierras roturables y no roturables. Ambos hechos adquieren cada día mayor relevancia, ya que este tipo de adscripción viene considerándose como la más idónea para salvaguardar a estos espacios montanos de los continuados abusos a que se ven sometidos por parte del conjunto de la sociedad. Así nos lo ha demostrado la evolución histórica de los aprovechamientos de esta montaña (Gómez Zotano, 2003, 2004). La explotación forestal en sus múltiples facetas (madera, resinas, corcho, etc.) ha sido el uso más importante de estos montes. Dichos aprovechamientos, tradicionales y sostenidos a lo largo de los siglos, parecen entrar en colisión con los objetivos de conservación estricta que pretenden ejercerse en estos espacios.

En este sentido, consideramos que los montes no han perdido su relevancia en la ordenación de estas montañas frente a los nuevos Espacios Naturales Protegidos. De hecho, la Ley de Montes resulta de vital importancia en estos Espacios Naturales dado que en todos ellos existen montes, arbolados o no, catalogados o no, sobre los que de alguna manera se realizan aprovechamientos de madera, leñas, pastos, etc. de modo secular.

Si se trata de los parques o parajes naturales, se puede afirmar que la legislación sobre montes proporciona una serie de herramientas y preceptos de extrema utilidad a la hora de conseguir los objetivos que plantea la RENPA, ya que en el fondo y en las formas persiguen lo mismo: Conservación, Uso Público y Aprovechamiento. Por consiguiente, carecen de sentido las fricciones que sistemáticamente aparecen entre la conservación de los espacios naturales protegidos cuando se aplican criterios estrictamente conservacionistas (de no actuación), y los aprovechamientos forestales que en él se puedan producir, obligatoriamente de manera ordenada según la propia ley que los regula.

Esto es sólo un ejemplo de cómo en realidad no existe o es prácticamente nula la colaboración con estamentos afines entre los que se podrían realizar importantes e interesantes proyectos, caso de la Reserva de Biosfera, Mancomunidad de Municipios de la Costa del Sol y de la Sierra de las Nieves, CEDER de la Serranía de Ronda y Sierra de las Nieves, CIT de la Serranía de Ronda y Sierra de las Nieves, Ayuntamientos, etc. Como apuntan Larrubia et al. (2001), estos espacios protegidos suponen una apuesta global del conjunto de administraciones competentes que deben gestionarlos bajo criterios de integración y sinergia. La problemática que conlleva la gestión de los espacios naturales de Sierra Bermeja y su costa no tolera soluciones parciales y exige una planificación que integre los factores e intereses implicados y que coordine la equilibrada vigencia de tales intereses. Sin embargo, cuando se analizan resultados y consecuencias se hace patente la falta de vinculación de las administraciones y la escasez de realizaciones prácticas. 
En este sentido cabe destacar la superposición de figuras sobre determinados espacios, así como el vacío legislativo que recae sobre otros de similares características, lo cual pone de manifiesto la falta de coordinación de estas iniciativas, consecuencia directa tanto del desconocimiento del medio, como de la inercia inherente a los límites político-administrativos, predominantes sobre los naturales.

\section{Bibliografía}

ARAQUE JIMÉNEZ, E. (1990): Los montes públicos en la Sierra de Segura. Siglos XIX y XX. Publicaciones del Instituto de Desarrollo Regional. Universidad de Granada. Granada, 215 pp.

GARZÓN BLANCO, A. (1999): La repoblación forestal en Málaga (1940-1980). Servicio de Publicaciones de la Diputación de Málaga. Málaga, 168 pp.

GÓMEZ-GUILLAMÓN Y MARAVER, L. (1967): Proyecto de Ordenación del monte «Sierra Blanca y Bermeja» de Igualeja, núm. 46 del Catálogo de los de Utilidad Pública de la provincia de Málaga. Ministerio de Agricultura. Dirección General de Montes, Caza y Pesca Fluvial. Málaga. (No publicado).

GÓMEZ-GUILLAMÓN Y MARAVER, L. (1971): Proyecto de Revisión Extraordinaria y primer Plan Especial Bis de aprovechamientos y mejoras de monte «El Pinar» de Casares, número 21 del Catálogo de los de Utilidad Pública de la provincia de Málaga. Ministerio de Agricultura. Dirección General de Montes, Caza y Pesca Fluvial. Málaga. (No publicado).

GÓMEZ-GUILLAMÓN Y MARAVER, L. (1972): Proyecto de Revisión Extraordinaria y segundo Plan Especial Bis de aprovechamientos y mejoras del monte «Sierra Bermeja» de Estepona, número 23 del Catálogo. Ministerio de Agricultura. Instituto Nacional para la Conservación de la Naturaleza. Málaga. (No publicado).

GÓMEZ-GUILLAMÓN Y MARAVER, L. (1973): «La Reserva Nacional de Caza de la Serranía de Ronda», en Jábega $\mathrm{n}^{\circ}$ 2, pp. 30-32.

GÓMEZ MORENO, M.L. (1987): «Los montes de propios y el desarrollo endógeno. Valoración ambiental y económica de los montes de propios de la provincia de Málaga», en Baetica $\mathrm{n}^{\circ} 10$, pp. 89-137.

GÓMEZ MORENO, M.L. (1989): La montaña malagueña. Estudio ambiental y evolución de su paisaje. Servicio de Publicaciones. Diputación Provincial de Málaga. Málaga, 412 pp.

GÓMEZ ZOTANO, J. (2003): «Conflictos en el Monte Mediterráneo: el caso de Sierra Bermeja (provincia de Málaga), la destrucción de un espacio de alto valor ecológico», en Las relaciones entre las comunidades agrícolas y el Monte. Ediciones de la Universidad de Castilla-La Mancha. Colección Humanidades, $\mathrm{n}^{\circ}$ 71, pp. 197-210.

GÓMEZ ZOTANO, J. (2004): El papel de los espacios montañosos como traspaís del litoral mediterráneo andaluz: el caso de Sierra Bermeja (provincia de Málaga). Universidad de Granada. Granada, 689 pp.

GÓMEZ ZOTANO, J. Y PANIZA CABRERA, A. (2003): «Análisis del sistema de protección ambiental de la Costa del Sol. Una frontera en litigio entre el espacio litoral y su trasfondo montañoso», en CyberGEO. European Journal of Geography n 250, pp. 1-14.

GUAITA, A. (1976): «Naturaleza jurídica de los montes catalogados del Estado y municipales de propios», en Conferencias sobre Derecho y Propiedad Forestal. Servicio de Publicaciones de la Escuela Técnica Superior de Ingenieros de Montes. Madrid, pp. 7-22.

ICONA (1991): Catálogo de los Montes Públicos exceptuados de la Desamortización: 1862. (Ed. Facs.). Madrid, 749 pp.

JIMÉNEZ MARTÍN, M.E. (2000): Ordenación del monte «Sierra Bermeja» de Jubrique, $n^{\circ} 25$ del Catálogo de Utilidad Pública de la provincia de Málaga. Proyecto Fin de Carrera. Universidad de Córdoba. (No publicado).

JUAN Y DÍAZ DE, C. (1965): Proyecto de Ordenación del Monte «Sierra del Real B». Término Municipal de Istán. Provincia de Málaga. Instituto Nacional de Previsión.

JUNTA DE ANDALUCÍA (1988): Plan Especial de Protección del Medio Físico y Catálogo de la Provincia de Málaga. Dirección General de Urbanismo. Sevilla, 437 pp. 
JUNTA DE ANDALUCÍA (1989): Plan Forestal Andaluz. Consejería de Agricultura y Pesca. Sevilla, $389 \mathrm{pp}$.

JUNTA DE ANDALUCÍA (1994): Plan de Ordenación de los Recursos Naturales y Plan Rector de Uso y Gestión del Parque Natural Sierra de las Nieves. Consejería de Medio Ambiente. Sevilla, $73 \mathrm{pp}$.

LARRUBIA VARGAS, R., NAVARRO RODRÍGUEZ, S. y LUQUE GIL, A. M. (2001): «Desarrollo sostenible en espacios protegidos. La comarca malagueña de la Sierra de las Nieves», en Cuadernos Geográficos no 31, pp. 173-200.

MÁRQUEZ FERNÁNDEZ, D. (1986): «El monte y sus transformaciones recientes», en Actas del III Coloquio Nacional de Geografía Agraria. Departamento de Geografía de la Universidad de Extremadura. Jarandilla de la Vera, pp. 7-23.

NEIRA, M. y MARTÍNEZ, F. (1973): Terminología forestal española. Publicaciones del Ministerio de Agricultura. Monografías INIA, $\mathrm{n}^{\circ} 1$. Madrid, $480 \mathrm{pp}$.

RODRÍGUEZ MARTÍNEZ, F. (1979): «Factores humanos en la evolución del paisaje vegetal de Andalucía. El caso de la Serranía de Ronda», en Actas del Primer Congreso de Historia de Andalucía. Andalucía Hoy. Publicaciones del Monte de Piedad y Caja de Ahorros de Córdoba. Córdoba, pp. 333-340.

RODRÍGUEZ MARTÍNEZ, F. (1985): Granada: medio físico y desarrollo. Publicaciones del Instituto de Desarrollo Regional. Granada, 239 pp. 